\title{
Communication and Patient safety
}

\section{Dixit SM}

Sanjaya Mani Dixit, Assistant Professor; Department of Pharmacology, Kathmandu Medical College Public Limited, Kathmandu, Nepal.

DOI: https://doi.org/10.3126/jkmc.v8i2.28161

he complexity in the healthcare system has increased tremendously in recent years and healthcare providers are more prone to make mistakes in complex systems.To address these issues and many others plaguing the healthcare system, the new discipline of patient safety has emerged ${ }^{1}$. Patient safety is focused on preventing and reducing risks, errors and ultimate harm to the patients. It works on the basis of continuous improvement by learning from errors and adverse events. "To err" is human and errors creep in especially in complex, high stress situations. So the concept of blaming the individual who made an active error for punishing is not good enough. Patient safety is rather aimed at developing an error-proof environment whereby the systems, tasks and processes in place filter out such errors. Safety of the patient is certainly at every healthcare professional's heart. No clinician wants to make mistakes and certainly no one wants to be at the receiving end when mistakes occur. Healthcare providers don't want anything to be detrimental for their patient. Many get heartbroken on losing patients from doctors to nurses, interns and medical students ${ }^{2,3}$. Yes, crying has been noted as an acceptable way of managing different kinds of stress at the hospitals. This may be for a dying patient, identifying with a patient's situation, or feeling overwhelmed by stress and emotions.

Patient safety is a relatively new field and insight from different areas is moving the science of patient safety forward. The lessons learnt from the aviation safety system has now been integrated into the patient safety systems in many parts of the world. It was first taken up by anaesthesiologists who adopted different theories and techniques of the aviation industry to ensure patient safety ${ }^{4}$.

It is said that the checklist in the aviation industry has paved a way for safer anaesthesia ${ }^{4}$. Sir Isaac Newton is known to have quoted "If I have seen further than

Address for correspondence

Mr. Sanjaya Mani Dixit

Assistant Professor, Department of Pharmacology

Kathmandu Medical College Public Limited, Duwakot, Bhaktapur

E-mail: sanjayadixit@gmail.com others, it is by standing upon the shoulders of giants". Yes, great science is built on the shoulders of giants, but again the giants should not be restricted to those from the same profession only and that we should be able to learn and implement good concepts and theories in a manner that transcends professions. People of today have already tried to solve the problems at hand using their professional expertise. It is only when we are able to have someone from another profession scrutinize our problems that our problems may find a solution, quite similar to the example of aviation industry helping anaesthesiologists. We do not exactly know whose ideas and expertise will enable us march forward in the coming years.

We are still far from embracing the safety culture in totality. There are multiple reasons behind it and proper communication or the lack of it is regarded as one major contributor fuelling to patient safety related problems ${ }^{5}$. Humans started talking to each other as early as 50000 years ago, some even debate it could be more than two million years before and as early as the beginning of the human genus Homo ${ }^{6}$. How is it even possible that we are still poor communicators at this age especially when the skill of communication is that old? Could it be because some of us are inherently bad at communication or because some of us can't communicate properly in the high stress situations of our work places namely hospitals and clinics? Is it that the ones who see and notice the problem with the patient don't feel like they have a say when it comes to patient care? How come the ones who see and notice the problem still not speak out? Does it have anything to do with our culture? Is it something in our culture that we are not able to communicate the serious issues to the consultants and senior doctors who are looking after the patients?

Mistakes are something that we do not notice on our own, we are good at pointing others' mistakes and vice-versa. We are comfortable pinpointing mistakes when communicating with friends or juniors, but are we comfortable communicating when we see a senior 
making a mistake? Do we, in our culture, easily pinpoint the mistakes of the seniors and the elderly? Do we have a hierarchical culture here in our country that hinders proper communication? Is it that we share the hierarchical culture from the airline industry that once plagued the Korean Air?

Korea is a country where the hierarchical culture is very prevalent and they are known to pay huge respect to their seniors. Koreans give utmost respect to the elderly and seniors. They are so good and humble to seniors that they simply do not and cannot speak against them. It was in the 1990s that this hierarchical culture was blamed for the lack of proper communication in the cabin crew in Korean Airlines which led to multiple crashes of their planes. Just imagine a person who knows he is going down with all others onboard still not sounding alarm and rather embracing death. That sounds quite impossible now, but that was exactly the case and can be traced to the air tragedies of Korean Air Cargo Flight 8509 in 1999 in which all four crew died. They had crashes just because the co-pilots could not sound alarms to the pilots owing to the hierarchy ${ }^{7}$. Another similar incident of Korean Air Flight 801 in 1997 that led to 228 deaths is also linked with improper communication in the cockpit owing to the hierarchical culture ${ }^{8}$.

Even in our culture we respect the seniors. Is it a deadly cocktail of our hierarchical culture and our hospitals where the only specialists are the doctors, making that the nurses and the other paramedics feel far too less

\section{REFERENCES}

1. Gandhi TK, Kaplan GS, Leape L, Berwick DM, EdgmanLevitan S, Edmondson A, et al. Transforming concepts in patient safety: a progress report. British Medical Journal Quality \& Safety [Internet]. 2018 [cited 8 December 2019]; 27(12):1019-1026. [DOI]

2. Sung AD, Collins ME, Smith AK, Sanders AM, Quinn $M A, B l o c k S D$, et al. Crying: Experiences and attitudes of third-year medical students and interns. Teaching \& Learning in Medicine. 2009 Jul;21(3):180-7. [PubMed]

3. Wagner RE, Hexel M, Bauer WW, Kropiunigg U. Crying in hospitals: a survey of doctors', nurses' and medical students' experience and attitudes. The Medical Journal of Australia [Internet]. 1997 Jan 6 [cited 2019 Dec 5];166(1):13-6. [PubMed]

4. Safety and Crisis in Aviation and in Anesthesiology Practice | Anesthesia Business Consultants [Internet]. [cited 2019 Dec 6]. [DOI] knowledgeable to check or communicate the errors even if they feel something wrong? Isn't it about time we think and tackle this shortcoming? Should we not assess if the culture of hierarchy is putting our patients at risk? Should we not do something to mitigate the hierarchy system at work places if that is a risk? May be one way is to increase the intake of healthcare professionals from other fields with a higher professional degree so that every professional body has expertise and command to express their views in the best interest of the ailing patients. Koreans brought about change in cockpit culture when they realized it was their hierarchical culture to blame. Should we not take similar steps in our healthcare system too so as to bring positive reform in the sector?

It is time to put patient safety first and march forward with the idea that all are equal when it comes to the healthcare providers and every other person has as essential role to play when it comes to patient care. World Health Organization promulgated the concept of health team approach in providing elderly patient care $^{9}$. Only the camaraderie approach not just in elderly patients but in all kinds of patients will make the healthcare providers believe that they have their say and thereby increase their input in patient care. It could be possible that having an easy and open environment at workplaces will bring forth the previously unheard voices thereby paving ways for effective communication within the team helping take patient safety ahead one step at a time.

5. Ross J. Effective Communication Improves Patient Safety. Journal of Perianesthesia Nursing. 2018 Apr 1;33(2):223-5. [DOI]

6. Balter M. Human language may have evolved to help our ancestors make tools [Internet]. Science. American Association for the Advancement of Science (AAAS); 2015 [cited 2019 Dec 5]. [DOI]

7. Halsey A.Lack of cockpit communication recalls 1999 Korean Airlines crash near London - The Washington Post [Internet]. [cited 2019 Dec 6]. [DOI]

8. Barren J.South Korean Plane Crashes On Guam With 254 on Board - The New York Times [Internet]. [cited 2019 Dec 6]. [DOI]

9. de Carvalho IA, Epping-Jordan JA, Pot AM, Kelley E, Toro N, Thiyagarajan JA, et al. Organizing integrated health-care services to meet older people's needs. Bulletin of World Health Organization. 2017 Nov 1;95(11):756-63. [Full text] 